\title{
TRATAMENTO DO DEJETO DE SUÍNO POR BIODIGESTÃO ANAEROBIA
}

\author{
Adriano Adelson Costa" \\ Francisco Rafael Martins Soto**
}

RESUMO: A suinocultura é uma atividade econômica de destaque no agronegócio brasileiro. Entretanto, a geração de efluentes em grande quantidade com potencial de poluição elevado caracteriza um obstáculo para o crescimento desta atividade. Diante deste cenário, este trabalho objetivou contextualizar a importância ambiental, econômica e sanitária do tratamento das dejeções suinícolas e descrever a tecnologia da biodigestão anaeróbia aplicada neste âmbito. A adoção da biodigestão anaeróbia se apresenta como uma alternativa eficiente para o tratamento destes dejetos. $\mathrm{O}$ uso de biodigestores promove um ambiente com condições anaeróbias que possibilita o desenvolvimento de bactérias hidrolíticas, acidogênicas, acetogênicas e metanogênicas que promovem a degradação da matéria orgânica e a reciclagem de nutrientes culminando na geração de subprodutos de valor agregado: biogás e biofertilizante, com desdobramentos ambientais, sanitários, econômicos e sociais positivos.

PALAVRAS-CHAVE: Biodigestores; Bioenergia; Biofertilizante; Gases de efeito estufa; Suinocultura.

\section{TREATMENT OF SWINE EXCREMENTS BY ANAEROBIC BIO- DIGESTION}

ABSTRACT. Swine-breeding is a highly appreciated economic activity in Brazilian agribusiness. However, the production of great amounts of effluents at high pollution rates is impairment for growth. Current study contextualizes the environmental, economic and sanitary importance for the treatment of swine excrement and forwards the technology of anaerobic bio-digestion applied to this end. Anaerobic bio-digestion is an efficient alternative for the treatments of such wastes. The employment of bio-digesters enhances a milieu with anaerobic conditions that makes

\footnotetext{
Mestrando em Saúde Ambiental pelo Centro Universitário das Faculdades Metropolitanas Unidas (FMU|FIAM-FAAM)..

** Médico Veterinário. Docente doutor nível DIII-III do Instituto Federal de Educação, Ciência e Tecnologia de São Paulo, Campus São Roque, Brasil.
} 
possible the development of hydrolytic, acidogenic, acetogenic and methanogenic bacteria that degrade organic matter and the recycling of nutrients, coupled to the production of value-aggregating byproducts such as biogas and bio-fertilizer, with positive environmental, sanitary, economic and social advantages.

KEY WORDS: Bio-digesters; Bioenergy; Biofertilizers; Hothouse gases; Swine breeding.

\section{INTRODUÇÃO}

A suinocultura é uma atividade econômica de relevante importância no agronegócio brasileiro. Seu crescimento propiciou o surgimento de granjas altamente tecnificadas, que permitem o aumento da produção deste tipo de proteína em áreas cada vez menores. Entretanto estas mudanças concentraram volumes crescentes de dejetos de suínos (DS) em pequenas áreas (DUDA; OLIVEIRA, 2011).

Estes DS gerados apresentam grande potencial poluidor devido à alta carga de matéria orgânica e a presença de grande quantidade de patógenos que apresentam riscos sanitários. A degradação não controlada destes DS, além de gerar danos ao bem-estar social devido aos odores gerados e à proliferação de vetores de doenças, acarreta na liberação de substâncias, como o metano $\left(\mathrm{CH}_{4}\right)$, gás carbônico $\left(\mathrm{CO}_{2}\right)$ e compostos nitrogenados (amônia, gases amônio, óxido nitroso e nitrogênio), que contribuem para a intensificação do efeito estufa (DIAS et al., 2013; SILVA; ITO; GUIMARÃES; AMARAL, 2016).

A biodigestão anaeróbia é apontada como uma importante forma de tratamento de DS, reduzindo sua carga de poluentes (nutrientes, matéria orgânica, patógenos) (HALMEMAN et al., 2014). Ela consiste em um processo natural e controlado, que ocorre na ausência de oxigênio, no qual micro-organismos anaeróbios degradam a matéria orgânica transformando-a, principalmente, em biogás e biofertilizante (ABREU, 2007; KLEINSTEUBER, 2014).

Embasado no potencial da biodigestão e visando explorar do ponto de vista ambiental e econômico os subprodutos gerados, foram desenvolvidos os biodigestores. Estes são equipamentos que oferecem condições ambientais propícias para 
o crescimento e manutenção de comunidades microbianas anaeróbias (AQUINO et al., 2014).

Desta forma, a partir desta tecnologia, é possível utilizar o biogás que consiste em um biocombustível com potencial para a geração de energia térmica e elétrica e o biofertilizante, este, rico em matéria orgânica previamente estabilizada, livre de patógenos e que funciona como melhorador de estruturas do solo, podendo, assim, ser aplicado na agricultura (RODRIGUEZ-VERDE, 2014).

A tecnologia da biodigestão anaeróbia representa uma alternativa promissora na solução de um dos maiores problemas enfrentados pelos suinocultores, que é a contaminação ambiental da atividade. Ademais, possibilita a geração de renda com o aproveitamento de subprodutos de valor agregado gerados, que podem produzir ganho econômico quando transformados em energia elétrica e ou térmica, créditos de carbono e biofertilizante. No aspecto sanitário e ambiental evita a contaminação de rios e solos, a liberação de odores e reduz a carga patogênica do material. Além destes aspectos, promove o sequestro do gás metano seguido da conversão deste em gás carbônico através da queima (BARBOSA; LANGER, 2011; MANNING; HADRICH, 2015).

Diante deste cenário, este trabalho teve por objetivo contextualizar a importância ambiental, econômica e sanitária do tratamento do DS e descrever a tecnologia de seu tratamento por meio da biodigestão anaeróbia.

\section{DESENVOLVIMENTO}

\subsection{IMPORTÂNCIA ECONÔMICA DA SUINOCULTURA}

A suinocultura é uma atividade econômica de importância mundial. No Brasil ela funciona como importante fator de geração de empregos. No ano de 2015 foram empregadas diretamente pela atividade 126 mil pessoas e indiretamente gerou cerca de 923.394 empregos (ABCS, 2016). As regiões Sul e Sudeste possuem destaque no cenário nacional em relação à produção de suínos. Juntas elas somam cerca de $85,57 \%$ do total de abates de suínos realizados no país, sendo que a região 
Sul engloba 69,3\% deste total, com distribuição estadual parcialmente uniforme, sendo Santa Catarina o Estado com maior número de abates (26,35\%) (ABPA, 2015).

No quesito produção mundial de carne suína, em 2016, o Brasil ficou na quarta colocação, com 3.731 mil toneladas, e com relação às exportações, o país ocupou a mesma posição, com 732 mil toneladas (ABPA, 2017). Segundo a Associação Brasileira de Criadores de Suínos (ABCS, 2016) o plantel reprodutivo brasileiro engloba 1.720.255 matrizes, que geraram 39.263.964 suínos para o abate em 2015. Esta produção gerou, de acordo com a ABCS, o equivalente a $\mathrm{R} \$ 62,576$ bilhões no que se refere ao Produto Interno Bruto (PIB) da suinocultura. Em relação a toda a cadeia produtiva de suínos foram movimentados no ano de 2015 cerca de $\mathrm{R} \$$ 149,867 bilhões.

A suinocultura nacional enfrenta alguns desafios para a sua expansão, como a falta de uma base sólida no mercado interno deste tipo de proteína, uma vez que a população consome mais carne bovina e de frango, e problemas com os modos de produção sustentável que promova fornecimento de carne suína que garanta segurança alimentar e com qualidade ambiental, social e sanitária (GASTARDELO; MELZ, 2014).

Entretanto, nos últimos anos, devido a uma procura crescente por este tipo de proteína em diversos países do mundo, a suinocultura apresentou relativo crescimento. Visando atender esta demanda, a atividade incorporou inovações tecnológicas que a permitiram produzir quantidades cada vez maiores em espaços reduzidos, desenvolvendo-se como suinocultura industrial (URBINATI; DUDA; OLIVEIRA, 2013). Porém, a situação levou a um passivo ambiental que consiste na geração de grande quantidade de DS, levando assim os produtores a terem dificuldades para a destinação ambientalmente correta destes resíduos, uma vez que possuem elevadas cargas poluidoras (DUDA; OLIVEIRA, 2011).

\subsection{IMPORTÂNCIA AMBIENTAL E SANITÁRIA DO DEJETO SUÍNO}

Os DS (fezes, urina, restos de ração e água) eliminados pelas granjas apresentam potencial poluidor devido, principalmente, à alta carga de matéria orgânica, nutrientes e à grande quantidade que é gerada por matriz instalada (BALOTA; MA- 
CHINESKI; MATOS, 2012). Silva et al. (2012) estabeleceram uma comparação entre a quantidade média de dejetos gerados por suínos com a quantidade média gerada pelos seres humanos. Nesta relação, um suíno defeca, em média, a quantidade equivalente a dejeções de cinco pessoas; assim, em um confinamento de 1.000 animais, há geração de DS equivalentes ao de uma cidade de 5.000 habitantes (SILVA et al., 2012).

Os DS podem apresentar diferentes formas de poluição no meio ambiente, especialmente em razão de suas características químicas. Como pode ser observado no Quadro 1 trata-se de efluente que contém elementos em quantidades potencialmente causadoras de diferentes danos ambientais.

Devido ao alto teor de nutrientes eles são utilizados na maioria das vezes na adubação de lavouras. Porém esta ação é realizada, geralmente, de forma inadequada, sem o devido tratamento (MOTTERAN; PEREIRA; CAMPOS et al., 2013). Há risco de poluição ambiental em regiões de produção intensiva devido, principalmente, à infiltração do nitrogênio no solo e ao escoamento superficial do fósforo e, muitas vezes, há o lançamento direto do DS nos corpos receptores (KUNZ; STEINMETZ; BORTOLI, 2010; MEDEIROS et al., 2011). Este procedimento poderá levar à mortandade de peixes e comprometimento do recurso hídrico por meio da eutrofização, devido às altas concentrações de matéria orgânica e de nitrato, além de outros componentes presentes (NETO; OLIVEIRA, 2009; PEREIRA et al., 2011).

Quadro 1. Composição química dos dejetos de suínos

\begin{tabular}{lccc}
\hline Parâmetro (variável) & Mínimo $(\mathbf{m g} / \mathbf{L})$ & Máximo $(\mathbf{m g} / \mathbf{L})$ & Média $(\mathbf{m g} / \mathbf{L})$ \\
\hline Sólidos totais & $11.530,2$ & $38.448,0$ & DQO 25.542,9 \\
\hline Sólidos voláteis & $12.697,0$ & $49.432,0$ & $22.399,0$ \\
\hline Sólidos fixos & $8.429,0$ & $39.024,0$ & $16.388,8$ \\
\hline Sólidos sedimentáveis & $4.268,0$ & $10.408,0$ & $6.010,2$ \\
\hline Nitrogênio total & 220,0 & 850,0 & 428,9 \\
\hline Fósforo total & $1.660,0$ & $3.710,0$ & $2.374,3$ \\
\hline Potássio total & 320,0 & $1.180,0$ & 577,8 \\
\hline
\end{tabular}

Fonte: De acordo com resultados obtidos por Silva (1996) na Unidade do Sistema de Tratamento de Dejetos da Embrapa, Concórdia (SC). 
Além de contaminar os recursos hídricos, a disposição inadequada dos DS é responsável pela poluição e comprometimento do solo. Os principais componentes dos DS que são responsáveis por este impacto são o nitrogênio, o fósforo e alguns microminerais, como o zinco e o cobre (SARDÁ et al., 2010). A principal explicação para este fato é a aplicação intensa de DS contendo grande quantidade de nutrientes que resultam na saturação do solo, dificultando sua capacidade de absorção e retenção, tornando-os assim menos férteis (NUNES et al., 2011; KUNZ et al., 2012).

Outro tipo de impacto que é causado pela disposição inadequada dos DS é aquele que afeta o bem-estar e a saúde humana, pois a decomposição não controlada destes resíduos contribui para a manutenção de bactérias do grupo coliforme, proliferação de moscas, ratos e outros vetores de doenças. Além disto, durante o processo de degradação são produzidos compostos voláteis, como os gases amônio, carbamato de amônia, amônia, dentre outros, que emitem odores desagradáveis e outros elementos que contribuem para o aquecimento global, devido geração dos gases do efeito estufa (GEE) (ORTIZ; VILLAMAR; VIDAL, 2014; ITO; GUIMARÃES; AMARAL, 2016).

Os sistemas agropecuários são responsáveis por grande parte das liberações de GEE, e a atividade suinícola, devido às suas particularidades, pode ser considerada como um dos principais geradores destes gases. Os principais gases liberados à atmosfera são o dióxido de carbono, gás metano, óxido de nitrogênio, amônia e outros gases traços. Eles são produzidos a partir da decomposição do DS por micro-organismos (ANGONESE; CAMPOS; WELTER, 2007).

Desta maneira se tal processo ocorrer de forma descontrolada, tais gases podem impactar a temperatura terrestre, uma vez que o metano e o óxido nitroso possuem potencial de aquecimento superiores ao principal GEE, que é o gás carbônico (RITTER; SANTOS; CURTI, 2013). De acordo com o relatório publicado em 1995 - Painel Intergovernamental sobre Mudanças Climáticas, a respeito das mudanças climáticas os gases metano e óxido nitroso apresentam, respectivamente, poder de aquecimento global 21 e 310 vezes maior que o $\mathrm{CO}_{2}$.

Ademais, estes GEE podem ficar ativos na atmosfera durante longos períodos e influenciar as mudanças climáticas, como a destruição da camada de ozônio, 
aumento da temperatura global e que pode levar ao derretimento de geleiras e o consequente aumento do nível dos oceanos (ANGONESE; CAMPOS; WELTER, 2007).

Diante desta situação, uma alternativa para evitar a liberação destes gases na forma de metano e óxido nitroso é a combustão dos mesmos. Este processo libera o gás carbônico resultante da queima do metano e $\mathrm{N}_{2}$ oriundo da combustão do óxido nitroso, entre outros compostos que são gerados. A queima do biogás resulta em uma quantidade expressiva de energia, podendo desta forma possuir aplicações interessantes na propriedade, e evita que o metano, um gás com elevado potencial de retenção de calor, seja liberado para a atmosfera (BARICHELLO et al., 2015).

Como já referenciado, a quantidade gerada de DS em uma granja de suínos é alta. Logo, a degradação destes DS contribuirá de forma expressiva para a liberação de GEE. Aquino et al. (2014) relataram que a cada tonelada de DS são produzidos em média $560 \mathrm{~m}^{3}$ de biogás. Portanto, é possível a utilização deste elemento como fonte energética.

\subsection{TRATAMENTO DO DS COM O USO DE BIODIGESTORES}

Com o objetivo de tornar a suinocultura sustentável, principalmente devido à sua tendência de crescimento cada vez maior (IPPERSIEL et al., 2012), percebeu-se a necessidade do emprego de tecnologias, como os biodigestores, para tratar de forma adequada os DS.

Os biodigestores são equipamentos cujo objetivo principal é a criação de um ambiente com condições propícias (ausência de oxigênio) para o desenvolvimento de bactérias anaeróbias que irão decompor e tratar a matéria orgânica que se encontra em seu interior, transformando-a em dois subprodutos principais: o biogás e o biofertilizante (DUARTE NETO et al., 2010).

Existe uma série de modelos de biodigestores, cada um com peculiaridades, porém os mais difundidos são o chinês, o indiano e o canadense (FERREIRA et al., 2011). Estes modelos são classificados ainda em dois tipos, de acordo com o fornecimento de biomassa: os contínuos (alimentação contínua) e os de batelada (fornecimento de biomassa apenas no início do processo de biodigestão com o esvaziamento no final do processo) (KHALID et al., 2011). 
O modelo canadense é o mais difundido atualmente no Brasil, principalmente pelo fato de ser de fácil instalação e de custo mais acessível podendo ser empregado para o tratamento de matéria orgânica tanto em propriedades grandes, quanto pequenas (JUNQUEIRA, 2014). E, além disto, este sistema quando comparado aos demais modelos é menos suscetível a corrosão pela água e pelo ácido sulfúrico que estão presentes no biogás. Já os modelos chinês e indiano são menos explorados devido ao fato de exigirem mão de obra mais especializada devido ao detalhamento da construção e por exigirem alocações de quantidades maiores de recursos o que aumenta o seu custo (GASPAR, 2003).

Os biodigestores além de serem equipamentos que proporcionam um ambiente favorável para a produção do biogás, eles o armazenam, para posteriormente ser utilizado como fonte de bioenergia, sendo transformada em energia elétrica e ou térmica e tendo como subproduto principal o gás carbônico, cerca de 21 vezes menos poluente para a atmosfera que o metano (RITTER; SANTOS; CURTI, 2013).

Os biodigestores representam equipamentos que contribuem para a integração da sustentabilidade do agronegócio no meio rural. Essa característica está ligada ao fato de que essas ferramentas permitem a transformação de resíduos com potencial de poluição alto em subprodutos de valor agregado (QUADROS et al., 2010).

Portanto, a aplicação desta tecnologia ajuda no desenvolvimento econômico da propriedade, permitindo exploração econômica do biogás e do biofertilizante pelo suinocultor garantindo retorno financeiro. Além disso, contribui também na promoção de credibilidade do empreendimento junto a órgãos governamentais, clientes e fornecedores (SILVA, 2009a; COLATTO; LANGER, 2011).

\subsection{BIODIGESTÃO ANAERÓBIA}

Os micro-organismos que atuam na biodigestão anaeróbia do DS são procarióticos anaeróbios facultativos e obrigatórios, e pertencem ao grupo de bactérias hidrolíticas, fermentativas acidogênicas, acetogênicas produtoras de hidrogênio e arqueas metanogênicas (ABREU, 2007; CHIODO et al., 2012). Cada um destes grupos irá atuar em uma fase específica no processo de biodigestão (Figura 1). 


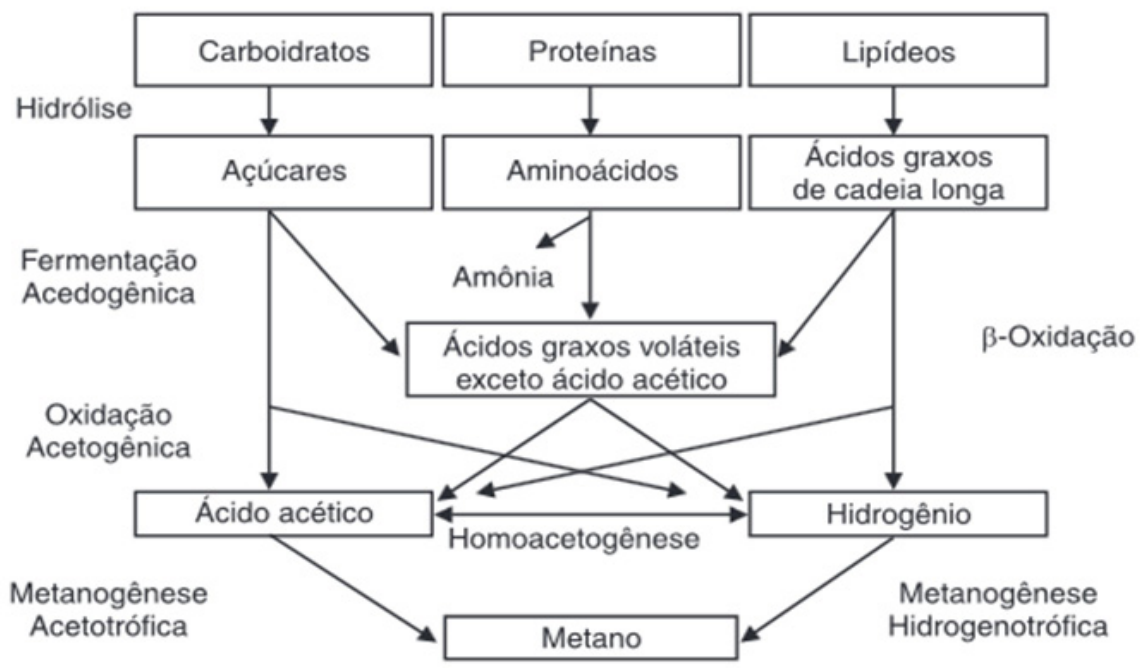

Figura 1. Etapas do processo de biodigestão anaeróbia.

Fonte: Adaptada de Salminen e Rintala (2002); Pavlostathis e Giraldo-Gomez (1991) apud Mendes et al. (2005).

A hidrólise constitui a primeira fase do processo da biodigestão e caracteriza-se pela atuação de bactérias fermentativas ou hidrolíticas. Nesta fase as substâncias complexas são convertidas em outras estruturas mais simples com baixo peso molecular através de exoenzimas que são enzimas secretadas pelas bactérias (SILVA, 2009b). As proteínas são decompostas em (poli) peptídeos, os carboidratos em açúcares solúveis (mono e dissacarídeos) e os lipídeos, por sua vez, em ácidos graxos de cadeia longa (C15 a C17) e glicerol (ABREU, 2007; REIS, 2012). Devido à presença de material particulado complexo, esta fase poderá ser dificultada, limitando todo o processo da biodigestão (SILVA, 2009b; REIS, 2012).

A fase dois é chamada de acidogênese ou fermentação. Nesta etapa os produtos resultantes da hidrólise são transformados por bactérias acidogênicas fermentativas em substâncias mais simples, como os ácidos graxos voláteis, alcoóis, ácido lático, gás carbônico, hidrogênio, amônia e sulfeto de hidrogênio (ZANETTE, 2009). No processo de acidogênese a maioria das bactérias são anaeróbias obrigatórias, existindo também espécies facultativas, no qual a matéria orgânica é metabolizada pela via oxidativa (SILVA, 2009b). Podem nesta fase atuar duas espécies de bactérias: Clostridium spp. e Bacteroids spp. (REIS, 2012). 
A acetogênese é a terceira fase do processo da biodigestão anaeróbia, onde ocorre a transformação dos produtos da acidogênese (alcoóis e ácidos graxos) pelas bactérias acetogênicas em acetato, hidrogênio e dióxido de carbono (SILVA, 2009b). $\mathrm{O}$ acetato e o hidrogênio são utilizados diretamente pelos micro-organismos responsáveis pela metanogênese, apresentando importância no processo (REIS, 2012).

A metanogênese é designada como a última etapa do processo de biodigestão anaeróbia. Ela consiste na transformação do acetato, dióxido de carbono e hidrogênio pelas bactérias metanogênicas em uma mistura de metano e dióxido de carbono (SILVA, 2009b; ZANETTE, 2009). Este sub processo envolve dois grupos de micro-organismos metanogênicos (ZANETTE, 2009; REIS, 2012). Os micro-organismos do primeiro grupo são chamados de acetoclásticos, como Methanosarcina spp. e Methanothrix spp., que transformam acetato e dióxido de carbono em metano $\left(\mathrm{CH}_{4}\right)$ (ZANETTE, 2009; REIS, 2012).

O segundo é composto por micro-organismos hidrogenotróficos, como Methanobacterium spp., Methanobrevibacter spp. e Methanospirillum spp., e utilizam o hidrogênio como doador de elétrons e o gás carbônico como aceptor de elétrons para produzir o gás metano $\left(\mathrm{CH}_{4}\right)$ (ZANETTE, 2009; REIS, 2012). As esquematizações abaixo descrevem as reações químicas referentes à atuação destes dois grupos na etapa da metanogênese (ABREU, 2007).

$$
\begin{gathered}
\text { Acetato } \rightarrow \text { metano } \quad \mathrm{CH} 3 \mathrm{COO}-+\mathrm{H}_{2} \mathrm{O}_{-} \mathrm{HCO} 3-+\mathrm{CH} 4 \\
\text { Hidrogênio } \rightarrow \text { metanoH2 }+1 / 4 \mathrm{HCO} 3-+1 / 4 \mathrm{H}+{ }_{-}^{1 / 4} \mathrm{CH} 4+3 / 4 \mathrm{H} 2 \mathrm{O}
\end{gathered}
$$

A biodigestão anaeróbia apresenta-se como um sistema ecológico interligado, pelo qual cada micro-organismo desempenha uma função que é importante para o resultado final (FARIAS et al., 2012). Esta sinergia do processo pode ser explicada pelo fato de que as bactérias metanogênicas dependem do substrato fornecido pelas acetogênicas, que são dependentes das acidogênicas e estas das hidrolíticas, estabelecendo-se um mecanismo de interações entre diversificados grupos de bactérias (SILVA, 2009b).

A fim de que este processo seja exitoso é fundamental que se tenham condições favoráveis que possibilitem o crescimento das comunidades bacterianas e, 
por consequência, a degradação da matéria orgânica. Para tanto é necessário considerar parâmetros como temperatura, $\mathrm{pH}$, nutrientes, umidade, materiais tóxicos e anaerobiose estrita. Em relação à temperatura nota-se que grandes variações podem levar à morte das bactérias digestoras. Neste caso, a faixa ideal é em torno de $37^{\circ} \mathrm{C}$ (faixa mesofílica) que é o intervalo no qual ocorre efetivamente a biodigestão. $\mathrm{O}$ pH deve estar situado entre 6,5 a 7,2; a umidade deve ser próxima de $90 \%$ e a presença de elementos como fosfato, enxofre, cálcio, magnésio, potássio, zinco e ferro são importantes para atender as necessidades nutricionais das bactérias (RIZZONI et al., 2012; ANDREAZZI; SANTOS; LAZARETTII, 2015).

\subsection{IMPORTÂNCIA ECONÔMICA DOS SUBPRODUTOS DA BIODIGESTAÇÃO ANAERÓBIA}

O biogás é um dos subprodutos do processo de biodigestão anaeróbia que apresenta potencial para ser utilizado como fonte de energia alternativa (COLATTO; LANGER, 2011; BUDZIANOWSKI, 2012). Este gás é composto basicamente de $60 \%$ a $75 \%$ de metano $\left(\mathrm{CH}_{4}\right), 25 \%$ a $40 \%$ de gás carbônico $\left(\mathrm{CO}_{2}\right)$ e alguns outros elementos traços, como sulfeto de hidrogênio $\left(\mathrm{H}_{2} \mathrm{~S}\right)$, gás amônia $\left(\mathrm{NH}_{3}\right)$, nitrogênio $\left(\mathrm{N}_{2}\right)$, entre outros (AVACI et al.; 2013). É um gás incolor e altamente combustível, com poder calorífico que pode variar de 5.000 a $7.000 \mathrm{Kcal}$ por metro cúbico (CERVI; ESPARANCINI; BUENO, 2010).

O volume de biogás que poderá ser produzido está relacionado a diferentes aspectos, como a qualidade do substrato envolvido e o grau de diluição (BARROS et al., 2009; RODRIGUES et al., 2014). O poder calorífico da mistura do biogás está relacionado à concentração de metano na mistura final, ou seja, quanto maior a concentração de metano na mistura final, maiores serão as possibilidades de utilização como fonte energética (SCHIAVON MAIA et al., 2014). E inversamente, quanto maior a concentração de gás carbônico menos poder calorífico terá a mistura (SOUZA et al., 2010).

O biogás apresenta-se com grande potencial na geração de energia renovável a ser utilizada tanto em áreas urbanas como rurais (CHENG, 2014). Uma vez que este gás pode ser aproveitado no próprio local, em cozimento, aquecimento, refrigeração, iluminação, incubadores, misturadores de ração, geradores de energia 
elétrica, entre outros (ZANETTE, 2009; YANG et al., 2014). Além do aproveitamento energético, o uso do biogás apresenta importância ambiental.

A utilização do biogás como fonte energética é apontada como uma solução econômica (FERNANDES et al., 2014). Pois permite um retorno financeiro para a propriedade que adotará tal tecnologia, devido à possibilidade de gerar energia elétrica e de venda de créditos de carbono que leva à obtenção de Certificados de Emissões Reduzidas (AMARAL et al., 2014). Com o Protocolo de Kyoto em vigor, o interesse em adotar os biodigestores se tornou ainda maior devido aos retornos monetários e por possibilitar a inserção da propriedade dentro do Mecanismo de Desenvolvimento Limpo (MDL), uma vez que reduz as emissões de GEE (BARICHELLO et al., 2015). Desta forma uma empresa que desenvolver projetos com a tecnologia da biodigestão anaeróbia e conseguir provar reduções de GEE durante a sua cadeia produtiva poderá captar recursos comercializando os créditos obtidos com corporações (SOUZA et al., 2012).

O biofertilizante é outro subproduto gerado simultaneamente com o biogás no processo de decomposição anaeróbia, possui aplicabilidade na agricultura e tem valor agregado (MONTORO; SANTOS; JUNIOR, 2013). Ele é um efluente clarificado mais estabilizado química e microbiologicamente, rico em húmus e quando aplicado no solo melhora sua estrutura física, química e biológica (RATHER; MUKHTAR, 2014).

O biofertilizante apresenta em sua composição, além de matéria orgânica, teor médio de $0,7 \%$ de nitrogênio, de $0,5 \%$ de fósforo e de $0,7 \%$ de potássio (BARBOSA; LANGER, 2011). Apresenta $\mathrm{pH}$ neutro que lhe confere propriedade importante na utilização deste produto na agricultura (MISHRA et al., 2013).

Este subproduto contribui para o melhoramento da estrutura e textura dos solos, aumento da porosidade e fluxo de oxigênio facilitando a respiração das raízes das plantas. Auxilia no aumento da fixação de nitrogênio pelos micro-organismos, diminui a perda de sais importantes para as plantas por meio da lixiviação, torna mais facilitada a absorção de nutrientes pelas plantas. Ademais, diminui os riscos potenciais de contaminação por coliformes termotolerantes e outros patógenos, devido ao fato dele ser um produto tratado pelo processo de digestão, entre outras funções (GOMES et al., 2014). 
Com relação ao aspecto sanitário, Abreu, Neto e Oliveira (2009) e Viancelli et al. (2013) relataram que a biodigestão anaeróbia foi capaz de reduzir de forma significativa o número de coliformes totais e de termotolerantes, que representam micro-organismos presentes no DS responsáveis por impactar de forma negativa a saúde humana.

Perante estas características torna-se possível a aplicação do biofertilizante originário de DS na produção agrícola. Considerando esta conjuntura, menciona-se o estudo realizado por Seidel et al. (2010) cujo objetivo foi analisar a produtividade e a absorção de nutrientes pela cultura do milho utilizando-se DS. Os autores obtiveram que tanto a aplicação dos DS como adubação de base como a adubação química (NPK) tiveram desempenho estatisticamente igual. Este resultado demonstrou que o DS é eficaz na produtividade da cultura do milho em sistema de plantio direto, o que o torna uma opção viável para o agricultor.

Já Factor, Araújo e Vilella Júnior (2008), que avaliaram a produtividade e a qualidade de frutos de pimentão vermelho híbrido 'Margarita' a partir do uso do efluente do biodigestor como substrato, identificaram que a substituição parcial de fertilizantes minerais pelo efluente de biodigestor à base de DS, não proporcionou a produtividade equivalente à adubação $100 \%$ mineral; porém, atingiu padrões de qualidade similares e com boa produtividade (FACTOR; ARAÚJO; VILELLA JÚNIOR, 2008).

\subsection{VIABILIDADE ECONÔMICA NA IMPLANTAÇÃO DE BIODIGESTORES}

Diante do exposto, pode-se afirmar que a biodigestão anaeróbia apresenta-se como uma alternativa promissora na promoção de gerenciamento ambientalmente adequado do DS. Apesar dos seus benefícios cientificamente comprovados, existem algumas variáveis, como viabilidade técnica e econômica, que podem ser consideradas pelos produtores como entraves para a implantação do sistema, especialmente quando se trata de pequenas produções.

Neste contexto, cita-se o trabalho desenvolvido por Cervi, Esperancini e Bueno (2010), que analisaram a viabilidade econômica do uso do biogás produzido em granja suinícola para geração de energia elétrica. Os autores utilizaram como dispositivo de estudo um biodigestor modelo tubular contínuo. Demonstraram ainda 
que o investimento inicial destinado à implantação foi estimado em $\mathrm{R} \$ \mathbf{5 1 . 5 3 7 , 1 7}$, e os custos anuais do sistema foram de $R \$$ 5.708,20 com manutenção, $R \$ 4.390,40$ com depreciação e $\mathrm{R} \$ 1.366,77$ com juros.

De acordo com as análises, o investimento é viável considerando a vertente econômica, desde que o consumo de energia elétrica seja de $35 \mathrm{kWh}$ por dia, em média. Assim o valor presente líquido (VLP) é de $\mathbf{R} \$ 9.494,90$, e a taxa interna de retorno (TIR) é de 9,34\% ao ano. Portanto, a viabilidade, de acordo com este estudo, depende da existência de atividades que demandem pelo uso de energia elétrica dentro da propriedade (CERVI; ESPERANCINI; BUENO, 2010).

O uso em sistemas de aquecimento é uma das formas indicadas para a utilização do biogás. Através desta medida é possível melhorar o sistema produtivo, especialmente no inverno, diminuindo, assim, a mortalidade de leitões, por exemplo (ANDREAZZI; SANTOS; LAZARETTI, 2015). Além da energia térmica, o biogás pode ser utilizado na geração de energia mecânica e elétrica, como descrito anteriormente.

Considerando ainda o quesito de aplicabilidade da tecnologia, cita-se o trabalho realizado por Dias et al. (2013). Eles avaliaram a viabilidade econômica da construção de biodigestores voltados para a produção de biogás a partir dos DS produzidos em uma granja de pequeno porte. Os valores estimados do investimento inicial no biodigestor, dos custos com depreciação e dos juros sobre o capital investidos foram, respectivamente, $R \$ 13.628,99, \mathrm{R} \$ 1.605,54$ e $\mathrm{R} \$ 539,03$.

Para analisar o retorno, os autores consideraram um cenário de 10 anos, que é o tempo médio de durabilidade deste tipo de projeto. Eles obtiveram como resultados dos indicadores econômicos: VPL $=\mathrm{R} \$ 57.598,95$, TIR $=48,38 \%$, Payback Simples $=2,06$ anos e Payback Descontado $=2,3$ anos. Com estes dados, Dias et al. (2013) demonstraram que a utilização da tecnologia é favorável, uma vez que possibilita a geração de benefícios econômicos, sociais e ambientais.

Já Zanin, Bagatini e Pessatto (2010) verificaram o tempo de retorno de um investimento equivalente a $\mathrm{R} \$$ 634.898,00 reais na implantação de um biodigestor. Apesar do alto valor, os autores identificaram como tempo de retorno para recuperar o investimento inicial o Payback Simples de 5,9 anos e Payback Descontado de 7,6 anos. Tais valores demonstraram a viabilidade econômica na utilização da tecnologia ambiental. 


\section{CONSIDERAÇÕES FINAIS}

A partir deste estudo de revisão conclui-se que a suinocultura é dicotômica: ao mesmo tempo que ela é uma atividade altamente poluidora, apresenta um grande espaço de crescimento econômico de forma sustentável.

A biodigestão anaeróbia apresenta-se como uma alternativa eficiente para 0 tratamento dos DS, pois garante a reciclagem da matéria orgânica através da geração do biogás e do biofertilizante que são subprodutos de valor agregado.

Os biodigestores são excelentes ferramentas que evitam a emissão do gás metano através da sua utilização como fonte energética, além de reduzir a poluição de solos, rios, lençóis freáticos e outros corpos receptores através da aplicação adequada do biofertilizante, promovendo assim a saúde pública e bem-estar social.

\section{REFERÊNCIAS}

ABREU, E. F. Estudo da diversidade microbiana metanogênica em reatores UASB tratando esgoto sanitário. 2007. Dissertação (Mestrado Saneamento, Meio Ambiente e Recursos Hídricos) - Universidade Federal de Minas Gerais, Belo Horizonte (MG). 2007.

ABREU NETO, M. S.; OLIVEIRA, R. A. de. Remoção de matéria orgânica, de nutrientes e de coliformes no processo anaeróbio em dois estágios (reator compartimentado seguido de reator UASB) para o tratamento de águas residuárias de suinocultura. Eng. Agríc., v. 29, n. 1, p. 148-161, 2009.

AMARAL, A. C.; KUNZ, A.; STEINMETZ, R. L. R.; CANTELLI, F.; SCUSSIATO, L. A.; JUSTI, K. C. Swine effluent treatment using anaerobic digestion at different loading rates. Engenharia Agrícola, v. 34, n. 3, p. 567-576, 2014.

ANDREAZZI, M. A.; SANTOS, J. M. G.; LAZARETTI, R. M. J. Estudo sobre a destinação dos resíduos da suinocultura em granjas do estado do Paraná. Electronic Journal of Management, Education and Environmental Technolog y (REGET), v. 19, n. 3, p. 744-751, 2015. 
ANGONESE, A. R.; CAMPOS, A. T.; WELTER, R. A. Potencial de redução de emissão de equivalente de carbono de uma unidade suinícola com biodigestor. Engenharia Agrícola, v. 27, n. 3, p. 648-657, 2007.

AQUINO, G. T.; BRONDANI, F. M. M.; SOUZA, R. A. A.; GERON, V. L. M. G. O uso do biogás no âmbito rural como proposta de desenvolvimento sustentável. Revista Científica da Faculdade de Educação e Meio Ambiente, v. 5, n. 1, p. 140-149, 2014.

ASSOCIAÇÃO BRASILEIRA DE PROTEÍNA ANIMAL (ABPA). Relatório Anual, 2017.

ASSOCIAÇÃO BRASILEIRA DE CRIADORES DE SÚINO (ABCS). Mapeamento da suinocultura brasileira. Brasília: ABCS, 2016.

AVACI, A. B.; SOUZA, S. N. M.; CHAVES, L. I.; NOGUEIRA, C. E. C.; NIEDZIALKOSKI, R. K.; SECCO, D. Avaliação econômico-financeira da microgeração de energia elétrica proveniente de biogás da suinocultura. Revista Brasileira de Engenharia Agrícola e Ambiental, v. 17, n. 4, p. 456-462, 2013.

BALOTA, E. L.; MACHINESKI, O.; MATOS, M. A. Soil microbial biomass under different tillage and levels of applied pig slurry. Revista Brasileira de Engenharia Agrícola e Ambiental, v. 16, n. 5, p. 487-495, 2012.

BARBOSA, G.; LANGER, M. Uso de biodigestores em propriedades rurais: uma alternativa à sustentabilidade ambiental. Unoesc \& Ciência-ACSA, v. 2, n. 1, p. 87-96, 2011.

BARICHELLO, R.; HOFFMANN, R.; SILVA, S. O. C.; DEIMLING, M. F.; CASAROTTO FILHO, N. O uso de biodigestores em pequenas e médias propriedades rurais com ênfase na agregação de valor: um estudo de caso na região noroeste do Rio Grande do Sul. Revista em Agronegócio e Meio Ambiente, v. 8, n. 2, p. 333-355, 2015.

BARROS, R. M.; TIAGO FILHO, G. L.; NASCIMENTO, Y. D. S.; GUSHIKEN, E.; CALHEIROS, H. C.; SILVA, F. G. B.; STANO JUNIOR, A. Estudo da Produção de biogás da digestão anaeróbica de esterco bovino em um biodigestor. Revista Brasileira de Energia, v. 15, n. 2, p. 95-116, 2009. 
BUDZIANOWSKI, W. M. Sustainable biogas energy in Poland: prospects and challenges. Renewable and Sustainable Energy Reviews, v. 16, n. 1, p. 342-349, 2012.

CERVI, R. G.; ESPARANCINI, M. S. T.; BUENO, O. Viabilidade econômica da utilização do biogás produzido em granja suinícola para geração de energia elétrica. Engenharia Agrícola, v. 30, n. 5, p. 831-844, 2010.

CHENG, S.; LI, Z.; MANG, H. P.; HUBA, L. M.; GAO, R.; WANG, X. Development and application of prefabricated biogas digesters in developing countries. Renewable and Sustainable Energy Reviews, v. 34, p. 387-400, 2014.

CHIODO, V.; URBANI, F.; GALVAGNO, A.; MONDELLO, N.; FRENNI, S. Analysis of biogas reforming process for molten carbonate fuel cells. Journal of Power Sources, v. 206, p. 215-221, 2012.

COLATTO, L.; LANGER, M. Biodigestor - resíduo sólido pecuário para produção de energia. Unoesc \& Ciência-ACET, v. 2, n. 2, p. 119-128, 2011.

DIAS, M. I. A.; COLEN, F.; FERNANDES, L. A.; SOUZA, R. M.; CARVALHO BUENO, O. Viabilidade econômica do uso do biogás proveniente da suinocultura, em substituição a fontes externas de energia. Energia na Agricultura, v. 28, n. 3, p. 155-164, 2013.

DUARTE NETO, E. D.; ALVARENGA, L. H.; COSTA, L. M.; NASCIMENTO, P. H.; SILVEIRA, R. Z.; LEITE, L. H. M. Implementação e avaliação de um biodigestor de produção descontínua. e-Xacta, v. 3, n. 2, p. 36-43, 2010.

DUDA, R. M.; OLIVEIRA, R. A. Tratamento de águas residuárias de suinocultura em reator UASB e filtro anaeróbico em série seguidos de um filtro biológico percolador. Engenharia Sanitária e Ambiental, v. 16, n. 1, p. 91-100, 2011.

FACTOR, T. L.; ARAÚJO, J. A. C.; VILELLA JR, L. V. E. Produção de pimentão em substratos e fertirrigação com efluente de biodigestor. Revista Brasileira de Engenharia Agrícola e Ambiental, v. 12, n. 2, p. 143-149, 2008.

FARIAS, R. M.; ORRICO JUNIOR, M. A. P.; ORRICO, A. C.; GARCIA, R. G.; CENTURION, S. R.; FERNANDES, A. R. M. Biodigestão anaeróbia de dejetos de poedeiras coletados após diferentes períodos de acúmulo. Ciência Rural, Santa Maria, v. 42, n. 6, p. 1089-1094, 2012. 
FERNANDES, D. M.; COSTANZI, R. N.; FEIDEN, A.; SOUZA, S. N. M.; KITAMURA, D. S. Processo de biodigestão anaeróbica em uma granja de suínos. Ambiência Guarapuava, v. 10, n. 3, p. 741-754, 2014.

FERREIRA, C. M.; FERNANDES, C. B.; SOUZA, A. V. S.; MELO, C. C. S.; SALES, J. S.; FRADE, M. L.; MACHADO, M. V.; FRADE, M. C.; GOMES, N. L.; COSTA, P. H. A.; MORAES, R. A.; ESTRELLA, T. G.; LIMA, M. C. P. B. Biodigestor para o gás do lixo orgânico. e-Xacta, v. 4, n. 2, p. 5-17, 2011.

GASTARDELO, T. A. R.; MELZ, L. J. A suinocultura industrial no mundo e no Brasil. Revista UNEMAT de contabilidade, v. 3, n. 6, 2014.

GASPAR, R. M. B. L. Utilização de biodigestores em pequenas e médias propriedades rurais com ênfase na agregação de valor: um estudo de caso na região de Toledo-PR. 2003. Dissertação (Mestrado em Engenharia de Produção) - Universidade Federal de Santa Catarina, Florianópolis (SC). 2003.

GOMES, L. P.; PERUZATTO, M.; SANTOS, V. S.; SELLITTO, M. A. Indicadores de sustentabilidade na avaliação de granjas suinícolas. Engenharia Sanitária e Ambiental, v. 19, n. 2, p. 143-154, 2014.

HALMEMAN, M. C. R.; STACHISSINI, M. G.; DAMACENO, F. M.; GABRIEL FILHO, L. R. A.; CREMASCO, C. P.; PUTTI, F. F. The deployment of biodigester systems in rural properties. Brazilian Journal of Biosystems Engineering, v. 8, n. 4, p. 351-360, 2014.

IPCC. Mudança do clima 1995: a ciência da mudança do clima: Brasília: MCT, 2000.

IPPERSIEL, D.; MONDOR, M.; LAMARCHE, F.; TREMBLAY, F.; DUBREUIL, J.; MASSE, L. Nitrogen potential recovery and concentration of ammonia from swine manure using electrodialysis coupled with air stripping. Journal of Environmental Management, v. 95, p. 165-169, 2012.

ITO, M.; GUIMARÃES, D.; AMARAL, G. Impactos ambientais da suinocultura:

desafios e oportunidades. BNDES Setorial, v. 44, p. 125-156, 2016.

JUNQUEIRA, S. L. C. D. Geração de energia através de biogás proveniente de esterco bovino: estudo de caso na Fazenda Aterrado. Monografia (Graduação em 
Engenharia Mecânica) - Universidade Federal do Rio de Janeiro, Rio de Janeiro (RJ). 2014.

KLEINSTEUBER, S. Special Issue on "Microbial Ecology of Anaerobic Digestion". Bioengineering, v. 1, p. 111-112, 2014.

KHALID, A.; ARSHAD, M.; ANJUM, M.; MAHMOOD, T.; DAWSON, L. The anaerobic digestion of solid organic waste. Waste Management, v. 31, n. 8, p. 1737-1744, 2011.

KUNZ, A.; STEINMETZ, R. L. R.; BORTOLI, M. Separação sólido-líquido em efluentes da suinocultura. Revista Brasileira de Engenharia Agrícola e Ambiental, v. 14, n. 11, p. 1220-1225, 2010.

KUNZ, A.; STEINMETZ, R.; DAMASCENO, S.; COLDEBELA, A. Nitrogen removal from swine wastewater by combining treated effluent with raw manure. Scientia Agricola, v. 69, n. 6, p. 352-356, 2012.

MANNING, D. T.; HADRICH, J. C. An evaluation of the social and private efficiency of adoption: Anaerobic digesters and greenhouse gas mitigation. Journal of environmental management, v. 154, p. 70-77, 2015.

MEDEIROS, S. S.; GHEYI, H. R.; PÉREZ-MARIN, A. M.; SOARES, F. A. L.; FERNANDES, D. P. Características químicas do solo sob algodoeiro em área que recebeu água residuária da suinocultura. Revista Brasileira de Ciência do Solo, v. 35, n. 3, p. 1047-1055, 2011.

MENDES, A. A.; CASTRO, H. F.; PEREIRA, E. B.; FURIGO JÚNIOR, A. Aplicação de lipases no tratamento de águas residuárias com elevados teores de lipídeos. Química Nova, v. 28, n. 2, p. 296-305, 2005.

MISHRA, D. J.; RAJVIR, S.; MISHRA, U. K.; KUMAR, S. S. Role of bio-fertilizer in organic agriculture: a review. Research Journal of Recent Sciences, v. 2277, p. 2502, 2013.

MONTANARI, T.; FINOCCHIO, E.; SALVATORE, E.; GARUTI, G.; GIORDANO, A.; PISTARINO, C.; BUSCA, G. CO 2 separation and landfill biogas upgrading: a comparison of 4A and 13X zeolite adsorbents. Energy, v. 36, n. 1, p. 314-319, 2011. 
MONTORO, S. B.; SANTOS, D. F. L.; JUNIOR, J. de L. Análise Econômica de Investimentos que visam à produção de biogás e biofertilizante por meio de biodigestão anaeróbia na bovinocultura de corte. RAUnP, v. 5, n. 2, p. 23-34, 2013.

MOTTERAN, F.; PEREIRA, E. L.; CAMPOS, C. M. M. The behaviour of an anaerobic baffled reactor (ABR) as the first stage in the biological treatment of hog farming effluents. Brazilian Journal of Chemical Engineering, v. 30, n. 2, p. 299-310, 2013.

NETO, M. S. A.; OLIVEIRA, R. A. Remoção de matéria orgânica, de nutrientes e de coliformes no processo anaeróbio em dois estágios (reator compartimentado seguido de reator UASB) para o tratamento de águas residuárias de suinocultura. Revista Engenharia Agrícola, v. 29, n. 1, p. 148-161, 2009.

NUNES, M. A. G.; KUNZ, A.; STEINMETZ, R. L. R.; PANIZ, J. N. G. Aplicação de efluente tratado de suinocultura para diluição de dejeto suíno e remoção de nitrogênio por desnitrificação. Engenharia Agrícola, v. 31, n. 2, p. 388-398, 2011.

ORTIZ, G.; VILLAMAR, C. A.; VIDAL, G. Odor from anaerobic digestion of swine slurry: influence of $\mathrm{pH}$, temperature and organic loading. Scientia agricola, v. 71, $\mathrm{n}$. 6, p. 443-450, 2014.

PEREIRA, E. L.; CAMPOS, C. M. M.; MONTERANI, F.; NETO, A. M. O. Eficiência de um sistema de reatores anaeróbios no tratamento de efluentes líquidos de suinocultura. Acta Scientiarum Technology, v. 33, n. 3, p. 287-293, 2011.

POESCHL, M.; WARD, S.; OWENDE, P. Environmental impacts of biogas deployment-Part I: Life cycle inventory for evaluation of production process emissions to air. Journal of Cleaner Production, v. 24, p. 168-183, 2012.

QUADROS, D. G.; OLIVER, A. P. M.; REGIS, U.; VALLADARES, R.; SOUZA, P. H. F.; FERREIRA, E. J. Biodigestão anaeróbia de dejetos de caprinos e ovinos em reator contínuo de PVC flexível. Revista Brasileira de Engenharia Agrícola e Ambiental, v. 14, n. 3, p. 326-332, 2010.

RATHER, S. A.; MUKHTAR, S. Environment and perception of sustainable agriculture development in India: the edge of bio-fertilizer. International Journal of Trade \& Global Business Perspectives, v. 3, n. 2, p. 1036-1041, 2014. 
REIS, A. S. Tratamento de resíduos sólidos orgânicos em biodigestor anaeróbio. 2012. Dissertação (Mestrado em Engenharia Civil e Ambiental) - Universidade Federal de Pernambuco, Recife. 2012.

RIZZONI, L. B. et al. Biodigestão anaeróbia no tratamento de dejetos de suínos. Revista Científica Eletrônica de Medicina Veterinária, v. 9, n. 18, p. 1-20, 2012.

PEREIRA SEIDEL, E.; GONÇALVES JUNIOR, A. C.; VANIN, J. P.; STREY, L.; SCHWANTES, D.; NACKE, H. Aplicação de dejetos de suínos na cultura do milho cultivado em sistema de plantio direto. Acta Scientiarum Technolog y, v. 32, v. 2, p. 113-117, 2010.

RITTER, C. M.; SANTOS, F. R.; CURTI, S. Potencial de produção de biogás com dejetos da suinocultura: sustentabilidade e alternativa energética em Santa Catarina. Tópos, v. 7, n. 1, p. 32-40, 2013.

RODRIGUES, J. P.; ORRICO, A. C. A.; ORRICO JÚNIOR, M. A. P.; SENO, L. O.; ARAÚJO, L. A.; SUNADA, N. S. Adição de óleo e lipase sobre a biodigestão anaeróbica de dejetos de suínos. Ciência Rural, v. 44, n. 3. p. 544-547, 2014.

RODRIGUEZ-VERDE, I.; REGUEIRO, L.; CARBALLA, M.; HOSPIDO, A.; LEMA, J. M. Assessing anaerobic co-digestion of pig manure with agroindustrial wastes: The link between environmental impacts and operational parameters. Science of the Total Environment, v. 497, p. 475-483, 2014.

SARDÁ, L. G.; HIGARASHI, M. M.; MULLER, S.; OLIVEIRA, P. A.; COMIN, J. J. Redução da emissão de $\mathrm{CO} 2$, $\mathrm{CH} 4$ e H2S através da compostagem de dejetos suínos. Revista Brasileira de Engenharia Agrícola e Ambiental, v. 14, n. 9, p. 1008-1013, 2010.

SCHIAVON MAIA, D. C.; LENZI, G. G.; ARROYO, P. A.; FRARE, L. M.; GIMENESES, M. L.; PEREIRA, N. C. Desenvolvimento de um sistema para purificação de biogás utilizando Fe/EDTA como absorvente. Engevista, v. 17, n. 2, p. 219-231, 2014.

SILVA, F. C. M. Tratamento dos dejetos suínos utilizando lagoas de alta taxa de degradação em batelada. 1996. Dissertação (Mestrado em Engenharia Ambiental) - Universidade Federal de Santa Catarinha, Florianópolis: UFSC, 1996. 
SILVA, F. P. O potencial energético e benefícios ambientais que trás um biodigestor indiano em uma criação de suínos em fase de terminação. 2009. Trabalho de conclusão (especialização em Fontes Alternativas de Energia) - Universidade Federal de Lavras, Lavras (MG). 2009a.

SILVA, A. A. Viabilidade técnica e econômica da implantação da biodigestão anaeróbia e aplicação de biofertilizante nos atributos de solo e plantas. 2009. Tese (Doutorado em Zootecnia) - Faculdade de Ciências Agrárias e Veterinárias, Universidade Estadual Paulista Júlio Mesquita Filho, Jaboticabal (SP). 2009b.

SILVA, W. T. L.; NOVAES, A. P.; KUROKI, V.; MARTELLI, L. F. A.; MAGNONI JÚNIOR, L. Avaliação físico-química de efluente gerado em biodigestor anaeróbio para fins de avaliação de eficiência e aplicação como fertilizante agrícola. Química Nova, v. 35, n. 1, p. 35-40, 2012.

SILVA, P. C.; AMARAL, A. A. Tratamento de dejetos de suínos com biorreator UASB. Revista verde de Agronegócio e Desenvolvimento Sustentável, v. 8, n. 5, p. 141$147,2013$.

SOUZA, R. G.; SILVA, F. M.; BASTOS, A. C. Desempenho de um conjunto motogerador adaptado a biogás. Revista de Ciência Agrotecnologia, v. 34, n. 1, p. 190-195, 2010.

SOUZA, A. L.; PAIVA, D. S.; ANDRADE, J. C. S.; SILVA JUNIOR, A. C.; GOULART, R. C. O Mercado Internacional de Créditos de Carbono: Estudo Comparativo entre as Vertentes Regulada e Voluntária no Brasil no Período de 2004 a 2011. Sistemas \& Gestão, v. 7, n. 4, p. 526-544, 2012.

URBINATI, E.; DUDA, R. M.; OLIVEIRA, R. A. Performance of UASB reactors in two stages under different HRT and OLR treating residual waters of swine farming. Engenharia Agrícola, v. 33, n. 2, p. 367-378, 2013.

VIANCELLI, A.; KUNZ, A.; STEINMMETZ, R. L. R.; KICH, J. D.; SOUZA, C. K.; CANAL, C. W.; COLDEBEllA, A.; ESTEVES, P. A.; BARARDI, C. R. M. Performance of two swine manure treatment systems on chemical composition and on the reduction of pathogens. Chemosphere, v. 90, n. 4, p. 1539-1544, 2013. 
YANG, L.; GE, X.; WAN, C.; YU, F.; LI, Y. Progress and perspectives in converting biogas to transportation fuels. Renewable and Sustainable Energ y Reviews, v. 40, p. 1133-1152, 2014.

ZANETTE, A. L. Potencial de aproveitamento energético do biogás no Brasil. 2009. Dissertação (Mestrado em Planejamento Energético) - Universidade Federal do Rio de Janeiro, Rio de Janeiro (RJ). 2009.

ZANIN, A.; BAGATINI, F. M.; PESSATTO, C. B. Viabilidade econômico-financeira de implantação de biodigestor - uma alternativa para reduzir os impactos ambientais causados pela suinocultura. Custos e @gronegócio on line, v. 6, n. 1, p. 121-139, 2010 .

Recebido em:06/10/2015 Aceito em: 01/10/2017 